\title{
Breastfeeding and Related Factors in Afrodescendant Women From Cartagena, Colombia
}

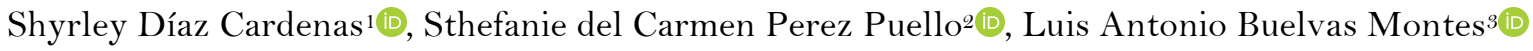

\begin{abstract}
${ }^{1}$ Department of Social and Community Dentistry, School of Dentistry, University of Cartagena, Cartagena, Bolivar, Colombia.

2Department of Social and Community Dentistry, School of Dentistry, Corporación Universitaria Rafael Núñez, Cartagena, Bolivar, Colombia.

${ }^{3}$ Department of Social and Community Dentistry, School of Dentistry, University of Cartagena, Cartagena, Bolivar, Colombia.
\end{abstract}

Author to whom correspondence should be addressed: Shyrley Díaz Cárdenas, School of Dentistry, University of Cartagena, Cartagena, Bolivar, Colombia. Phone: +5756698172. E-mail: sdiazc@unicartagena.edu.co.

Academic Editors: Alessandro Leite Cavalcanti and Wilton Wilney Nascimento Padilha

Received: 30 October 2019 / Accepted: 09 March 2020 / Published: 18 March 2020

How to cite this article: Cardenas SD, Puello SCP, Montes LAB. Breastfeeding and related factors in afrodescendant
women from Cartagena, Colombia. Pesqui Bras Odontopediatria Clín Integr. 2020; $20: e 5359$.
https://doi.org/10.1590/pboci.2020.049

\begin{abstract}
Objective: To describe practices and related factors to breastfeeding in afrodescendant women from Cartagena de Indias city, Colombia. Material and Methods: Cross-sectional study conducted between 2016 and 2017 in 548 mothers who had under 5 years children from afrodescendant communities. A self-reported questionnaire was applied, asking for sociodemographic variables, breastfeeding time and exclusive breastfeeding, family support and factors related to this practice. Data were analyzed by descriptive statistics and risk estimation by Odds Ratio (OR). Results: Most mothers were young adults (89.8\%), having high scholar level $(55.2 \%)$, family support and they were associated to the public health system. The prevalence of breastfeeding and exclusive breastfeeding during the first 6 months was $91.6 \%$ and $80.4 \%$, respectively. Breastfeeding and exclusive breastfeeding practice were associated with mother's age $(\mathrm{OR}=$ $3.24,95 \% \mathrm{CI}=1.80-5.8)$ and low mother's educational level $(\mathrm{OR}=3.24,95 \% \mathrm{CI}=1.8-5.8)$. Finally, no breastfeeding and the fact of not being performed exclusively was associated with no mother nipples examination, and not or insufficient information supplied about this issue. Conclusion: Breastfeeding practice was associated with mother's age and her educational level as well as with poor preparation to start this practice. Although its prevalence was high, it is necessary to implement policies within health system to encourage its practice and provide measures to solve problems during their development in mothers from vulnerable communities.
\end{abstract}

Keywords: Feeding Behavior; Breast Feeding; Infant Health; Child Health. 


\section{Introduction}

Since first months of life, the infant needs to acquire all the nutrients through diet that allows him to develop his vital functions and healthy growth [1]. Due to their components, properties and advantages, breast milk has become the best exclusive natural food during the first 6 months of life and as complementary food until two years [2]. Breast milk contains nutrients, which promote sensory and cognitive development as well as immune protection, behaving as an anti-infective and anti-inflammatory feed [3]. Therefore, exclusive breastfeeding protects the infant from infectious diseases such as diarrhea and pneumonia that are prevalent in childhood, being the main reason of death [4].

The World Health Organization (WHO) and the United Nations Children's Fund (UNICEF) have developed several strategies such as integrated management of childhood illness (IMCI) and baby friendly hospitals initiative (BFHI), both aims to reduce mortality rates during childhood. In addition, they promote the implementation of exclusive breastfeeding and other protective practices since first hours of life of infant by promoting better habits in mother and child [5-7].

Despite the implementation of "De cero a siempre" law (Law 1804 August 2, 2016) in the health ministry of Colombia, which develops concepts and techniques that allow the protection and comprehensive development of early childhood, there is no evidence related to decrease in mortality rates. According to the National Administrative Department (DANE), there was an increase about $1.4 \%$ in death rates, going from 47.250 to 47.875 cases between 2014 and 2015 [8]. Based on this data, it is necessary to continue adopting strategies and support groups to incentive breastfeeding as a protective practice. In addition, the implementation of policies that fully benefit to newborns and their mothers. International literature relates breastfeeding with factors such as age and mother scholar level, coexistence with father, prenatal guidance on breastfeeding, postpartum counseling and problems related to breastfeeding which could intervene and generate an early end-up [9-11].

However, from a local perspective, few studies describe the factors which could intervene in the adequate development of breastfeeding and they also report means below recommended. According to the national nutritional status survey in Colombia (2010) and press release No 288/2013 from Colombian Ministry of Health and Social Protection, the average duration of breastfeeding was 14.9 months in 2010. The average of exclusive breastfeeding was 1.8 months, which does not fulfill WHO recommendation, around 24 months for breastfeeding and 6 months for exclusive breastfeeding.

Regarding breastfeeding factors in Colombian population, the studies reported that not using baby bottle had an association with a longer exclusive breastfeeding. At the same time, the variable that best explained the model was non-bottle use, which was significantly associated with breastfeeding. Therefore, its use should be reduced by providing suitable information to mothers as well as by implementation of actions in health service to increase the number of mothers who perform this practice $[12,13]$.

Hence, in order to increase scientific evidence that allows to improve interventions and encourage breastfeeding practice, the aim of the present study was to describe the practices and related factors to breastfeeding in afrodescendant communities from La Boquilla, Manzanillo, Tierra Baja and Caño del Oro in Cartagena de Indias city, Colombia. The population was constituted by pregnant women and children under 5 years old under vulnerability conditions, which could increase mortality and the risk of acquiring diseases compromising their quality of life.

\section{Material and Methods}




\section{Study Design}

A cross-sectional descriptive study was conducted between 2016 and 2017, in the La Boquilla, Manzanillo, Tierra Baja and Caño del Oro community, coastal populations from Cartagena de Indias city, Colombia.

Population

The universe population was constituted by 600 families distributed between these communities. Main selection criteria of this study were mother having children under 5 years old and they have to accept their participation through written informed consent. Conversely, mothers who had children who present chronic diseases or disabilities that might compromise the normal development of breastfeeding were excluded. In total, the study sample was constituted by 548 mothers who had under 5-years children and they were selected by convenience whether they were present during home visit and if they accepted their voluntary participation in this study. Participants completed a written informed consent, as expressed in resolution 8430 of 1993 from the Colombia Ministry of Health and Social Protection and the Declaration of Helsinki.

\section{Data Collection}

Data collection was performed during home visit, using a self-administered questionnaire, previously calibrated and validated in a population having similar sociodemographic characteristics to investigated sample in the current study. It also inquired about mothers' socio-demographic characteristics: age (under 19 years or 20 to 44 years), mother education ( $\geq 10$ years of study or $<10$ year of study), number of children (from 1 to 2 sons or $\geq 3$ sons), cohabitation with husband (yes or no), cohabitation with grandmother (yes or no), health system (public or private) [9-11]. In addition, the questionnaire included other factors such as: practices related to breastfeeding (yes or no), exclusive breastfeeding (yes or no), information received during prenatal courses (yes or no), information received during hospital stay (yes or no), provided information was enough (yes or no), nipples examination (yes or no), capability to explain to another mother how breastfeeding process occurs (yes or no), knowledge about where to go when breastfeeding related problems happened (yes or no), found counseling to solve the problem (yes or no), knowledge about support groups on breastfeeding (yes or no) [9-11]. During evaluation time, one point was given to adequate practices whereas inadequates ones received no point in the instrument.

\section{Data Analysis}

For data processing and analysis, Microsoft Office Excel 2016 (Microsoft Corporation, Redmond, Washington, USA) and STATA 11.2 (Stata Corp, College Station, TX, USA) programs were used. Data were analyzed by descriptive statistics and odds ratio $(\mathrm{OR})$ associations were estimated, assuming $95 \%$ confidence intervals.

\section{Ethical Clearance}

This study was approved by the Ethics Committee for Human Studies from University of Cartagena.

\section{Results}


Most mothers were young adult with an average age of $26.7 \pm 0.3$ years and studied 10 years or more (55.2\%). In addition, they had between 1 and 2 children (71.5\%), and affirmed to live with their partner (78\%), with child grandmother (55.8\%) and belonged to health public system (86.8\%) (Table 1$)$.

Table 1. Socio-demographic characteristics of mothers.

\begin{tabular}{lcc}
\hline \multicolumn{1}{c}{ Variables } & N & $\%$ \\
\hline Age & 56 & 10.1 \\
$\quad$ Under 19 Years & 492 & 89.8 \\
$\quad \begin{array}{l}\text { 20-44 Years } \\
\text { Mother Education }\end{array}$ & \\
$\quad \geq 10$ Years of Study & 303 & 55.2 \\
$\quad<$ 10 Years of Study & 245 & 44.7 \\
Number of Children & & \\
$\quad$ 1-2 Sons & 392 & 71.5 \\
$\quad \geq 3$ Sons & 156 & 28.4 \\
Cohabitation with Husband & & \\
$\quad$ Yes & 428 & 28.0 \\
$\quad$ No & 120 & \\
Cohabitation with Grandmother & & 55.8 \\
$\quad$ Yes & 306 & 44.1 \\
$\quad$ No & 242 & 86.8 \\
Health System & & 13.1 \\
$\quad \begin{array}{l}\text { Public } \\
\text { Private }\end{array}$
\end{tabular}

The breastfeeding prevalence was 91.6\% (95\% CI: 89.3-94.0) while $80.4 \%$ of mothers (CI 95\%: $77.0-$ 83.7) breastfed exclusively for at least 6 months. In relation to support received by the health personnel during breastfeeding, the mothers reported to received clear information during prenatal courses (60.2\%) and postpartum hospital stay (63.2\%). However, they affirmed that provided information was not enough (52.3\%), consequently they would not be able to explain to another mother how breastfeeding process occurs (50.6\%). In addition, $60.6 \%$ of mothers stated that they did not know where to go when having a breastfeeding related problem. In addition, they did not know about the existence of support groups $(67.8 \%)$ that provide training and advice to conduct this practice. Finally, problems related to breastfeeding were not solved in $68.7 \%$ cases when they were attended in their health systems (Table 2).

Table 2. Practices related to breastfeeding mothers.

\begin{tabular}{lcc}
\multicolumn{1}{c}{ Variables } & N (\%) & CI 95\% \\
\hline Breastfeeding & $502(91.6)$ & $89.3-94.0$ \\
$\quad$ Yes & $46(8.4)$ & $5.9-10.6$ \\
$\quad$ No & & \\
Exclusive Breastfeeding & $441(80.4)$ & $77.0-83.7$ \\
$\quad$ Yes & $107(19.5)$ & $16.2-22.9$ \\
$\quad$ No & & \\
Information During Prenatal Courses & $330(60.2)$ & $56.1-64.3$ \\
$\quad$ Yes & $218(39.7)$ & $35.6-43.8$ \\
$\quad$ No & & \\
Information During Hospital Stay & $347(63.2)$ & $59.1-67.2$ \\
$\quad$ Yes & $201(36.7)$ & $32.7-40.8$
\end{tabular}


Provided Information was not Enough

\begin{tabular}{|c|c|c|}
\hline Yes & $261(47.6)$ & $43.4-51.9$ \\
\hline No & $287(52.3)$ & $48.0-56.5$ \\
\hline \multicolumn{3}{|c|}{ ipples Examination } \\
\hline Yes & $330(60.2)$ & $56.1-64.3$ \\
\hline No & $218(39.7)$ & $49.7-58.1$ \\
\hline \multicolumn{3}{|c|}{ xplain to Another Mother how Breastfeeding Process Occurs } \\
\hline Yes & $271(49.3)$ & $45.1-53.5$ \\
\hline No & $277(50.6)$ & $46.4-54.8$ \\
\hline \multicolumn{3}{|c|}{ now Where to go went Breastfeeding Related Problems Happened } \\
\hline Yes & $216(39.3)$ & $35.2-43.5$ \\
\hline No & $332(60.6)$ & $56.4-64.7$ \\
\hline \multicolumn{3}{|c|}{ ound Counseling to Solve the Problem } \\
\hline Yes & $171(31.2)$ & $27.3-35.1$ \\
\hline No & $377(68.7)$ & $64.8-72.6$ \\
\hline \multicolumn{3}{|c|}{ now Support Groups for Breastfeeding } \\
\hline Yes & $176(32.1)$ & 28.2-36.1 \\
\hline No & $372(67.8)$ & $63.8-71.7$ \\
\hline
\end{tabular}

Statistically significant associations between breastfeeding practice and being adolescent $(\mathrm{p}=0.02, \mathrm{OR}$ $=2.41,95 \% \mathrm{CI}=1.2-5.4)$ and low education level of the mother $(\mathrm{p}=0.01, \mathrm{OR}=2.15,95 \% \mathrm{CI}=1.1-4.0)$ were found. When analyzing breastfeeding practice with related factors, not breastfeeding to child was associated with no information provided by personnel from health system $(\mathrm{p}=0.01$, OR $=2.10,95 \% \mathrm{CI}=1.13-3.88)$ and no sufficient information was supplied for the implementation of this practice $(\mathrm{p}=0.04, \mathrm{OR}=1.91,95 \% \mathrm{CI}=$ 1.0-3.64) (Table 3).

Table 3. Association between breastfeeding practice, sociodemographic variables and related factors.

\begin{tabular}{lcc}
\multicolumn{1}{c}{ Variables } & OR (CI 95\%) & p-value \\
\hline Age & & $0.02^{*}$ \\
$\quad$ Under 19 Years & $2.41(1.2-5.4)$ & - \\
$\quad$ 20-44 Years & - & $0.01^{*}$ \\
Mother Education & $2.15(1.1-4.0)$ & - \\
$\quad<10$ Years of Study & - & - \\
$\quad \geq 10$ Years of Study & - & 0.70 \\
Number of Children & $1.13(0.58-2.20)$ & - \\
$\quad$ 1-2 Sons & & 0.33 \\
$\quad \geq 3$ Sons & - & - \\
Cohabitation with Husband & $1.1(0.60-2.0)$ & 0.74 \\
$\quad$ Yes & & - \\
$\quad$ No & & - \\
Cohabitation with Grandmother & $1.10(0.60-2.0)$ & - \\
$\quad$ Yes & & - \\
$\quad$ No & & $0.01^{*}$
\end{tabular}


Provided Information was not Enough

Yes

No

$.91(1.0-3.64)$

$0.04^{*}$

Explain to Another Mother How Breastfeeding Process Occurs

Yes

No

$1.5(0.82-2.84)$

0.18

Know Where to go went Breastfeeding Related Problems Happened Yes

No

$1.8(0.93-3.65)$

0.07

Found Counseling to Solve the Problem

Yes

No

$1.12(0.57-2.21)$

0.72

Know Support Groups for Breastfeeding Yes

No

$1.48(0.73-2.99)$

0.27

*Statistically significant.

At the same time, no exclusive breastfeeding during the first six months of life was associated with being adolescent $(\mathrm{p}<0.01, \mathrm{OR}=3.24,95 \%$ CI 1.80-5.8) and low educational level of the mother $(\mathrm{p}<0.01, \mathrm{OR}=$ $3.24,95 \% \mathrm{CI}=1.8-5.8)$. Finally, no exclusive breastfeeding during the first six months was associated with no nipple examination $(\mathrm{p}=0.03, \mathrm{OR}=1.61,95 \% \mathrm{CI}=1.04-2.49)$, no information received at the hospital $(\mathrm{p}<0.01$, $\mathrm{OR}=2.18,95 \% \mathrm{CI}=1.42-3.35)$ and insufficient information provided by personnel from health system $(\mathrm{p}=0.01, \mathrm{OR}=1.73$, CI 95\% $=1.12-2.68)($ Table 4$)$.

Table 4. Association between breastfeeding during the first 6 months, sociodemographic variables and related factors.

\begin{tabular}{|c|c|c|}
\hline Variables & OR (CI 95\%) & p-value \\
\hline \multicolumn{3}{|l|}{ Age } \\
\hline Under 19 Years & $3.24(1.80-5.8)$ & $<0.01^{*}$ \\
\hline 20-44 Years & - & - \\
\hline \multicolumn{3}{|l|}{ Mother Education } \\
\hline$<10$ Years of Study & $3.24(1.80-5.8)$ & $<0.01 *$ \\
\hline$\geq 10$ Year of Study & - & - \\
\hline \multicolumn{3}{|l|}{ Number of Children } \\
\hline 1-2 Sons & - & - \\
\hline$\geq 3$ Sons & $0.63(0.38-1.0)$ & 0.08 \\
\hline \multicolumn{3}{|l|}{ Cohabitation with Husband } \\
\hline Yes & - & - \\
\hline No & $1.4(0.89-2.3)$ & 0.20 \\
\hline \multicolumn{3}{|l|}{ Cohabitation with Grandmother } \\
\hline Yes & - & - \\
\hline No & $0.78(0.51-1.21)$ & 0.20 \\
\hline \multicolumn{3}{|l|}{ Information During Prenatal Courses } \\
\hline Yes & - & - \\
\hline No & $1.13(0.73-1.74)$ & 0.56 \\
\hline \multicolumn{3}{|l|}{ Nipples Examination } \\
\hline Yes & - & - \\
\hline No & $1.61(1.04-2.49)$ & $0.03 *$ \\
\hline \multicolumn{3}{|l|}{ Information During Hospital Stay } \\
\hline Yes & - & - \\
\hline No & $2.18(1.42-3.35)$ & $<0.01^{*}$ \\
\hline
\end{tabular}


Provided Information was not Enough

Yes

No

Explain to Another Mother How Breastfeeding Process Occurs

Yes

No

now Where to go went Breastfeeding Related Problems Happened

Yes

No

Found Counseling to Solve the Problem

Yes

No

Know Support Groups for Breastfeeding

Yes

No

*Statistically significant

\section{Discussion}

This research corresponds to the first study regarding breastfeeding practice conducted on AfroColombian population that is considered a vulnerable community. Hence, the implementation of protective practices such as breastfeeding for children under 5 years and their mothers are needed. Thus, it was observed that the frequency of breastfeeding and exclusive breastfeeding practice were high. In addition, factors such as being adolescent and having a low education level were variables associated with risk factors for not to perform this practice. Also, adolescent mothers with low educational level did not know the benefits of breastfeeding for infants. In addition, beliefs related to this practice, lack of family support and insufficient assistance from health system personnel during their execution could lead to early abandonment. Conversely, several studies have shown that the higher the education level, there is an increase in the number of mothers who breastfeed their infants for more than one month [14,15], which matches with the findings of the current study. However, in the United States, some authors found a greater probability of breastfeeding abandonment or not performing this practice among mothers who had high education levels and better job opportunities, which represents a reason for maternity leave ending $[15,16]$. The differences found among the studies are probably related to factors variability in the different cultural contexts and various woman roles in the society.

Some studies reported that mothers who had higher education levels will have a better knowledge about breastfeeding benefits for both, they and their children, which makes they more aware about the importance of this practice $[17,18]$. Also, the high education level among mothers can improve the quality of life of child and will be determinant in aspects such as food habits during the early stages of life [19]. In this way, mothers who have higher education levels, may be more aware about the importance of their maternal role, have a greater possibility of access to health systems services and receive education in relation to protective practices in health [20,21].

Others studies reported that presence of friends, mother-in-law, sister, father, pediatrician, organizations and support groups were associated to breastfeeding duration [22-25]. Some authors presented similar results, emphasizing that baby's father support facilitated breastfeeding process [26]. Institutions, groups or individuals enrolled in the knowledges transference about breastfeeding should prioritize care in younger pregnant women, without neglecting the older ones. In addition, it is important to deepen in issues related to manual techniques of breast milk extraction, conservation, breastmilk bank, strategies to favor breastfeeding and the best positions among others [27]. Therefore, it is suggested to carry out observational 
studies in pregnant women in order to evaluate if strategies and public policies implemented to encourage this practice are effective and allow their execution exclusively during the first 6 months and complements up to 2 years.

In our study, non-exclusive breastfeeding practice during the first six months presented association with being adolescent, insuficient information provided by personnel from health system and no nipples examination. Additionally, others studies observed that adolescent mothers have little intention to breastfeed as well as problems related to breasts and breast milk production, as well as a greater tendency to abandon prematurely the practice of exclusive breastfeeding [28,29]. However, grandmother support was a protective factor that prolonged the development of breastfeeding practice [29]. The fact of being adolescent mothers is a risk factor for breastfeeding and exclusive breastfeeding because they have physiological and psychological immaturity. Also, the pregnancy is usually unplanned at this stage, which represents parents negligence and child misconduct in the future [30]. Therefore, it is necessary to implement health policies to prevent pregnancy at an early age. In addition, the development of multidisciplinary teams that provide support to mother since prenatal stage and identify possible risk factors that could interfere in breastfeeding practice.

The deficient practical information about breastfeeding techniques causes inconveniences to the mother and child during breastfeeding execution and its consequent early abandonment [31]. This situation was observed in the present study because the information regarding breastfeeding offered by personnel from health services is not received properly or it is incomplete. Therefore, mothers do not know how to solve the problems presented during breastfeeding practice, which generates discomfort, nipples inflammation and early withdrawals during the process, finding an association with the lack of an adequate breastfeeding practice.

Probably, women with inadequate prenatal care had not received prenatal care as recommended by clinical practice guidelines, which generates preoccupation due to prenatal importance to mother and child health $[32,33]$. Also, due to the fact of not receiving adequate information, mothers were not able to explain to other pregnant women how the breastfeeding techniques should be performed, factor associated with nonperformance of the practice. The feedback process of breastfeeding practice with other mothers corresponds to strategies performed from programs that promote breastfeeding such as BFHI and IMCI strategies related to early childhood health for increasing the frequency of breastfeeding and decreasing infant morbidity and mortality rates [5,34,35]. It is also observed that education on breastfeeding is limited in promotion and prevention programs from health institutions through antenatal class. However, during childbirth and postpartum stay at the hospital, the mother and her child need support and counseling about breastfeeding beginning, instructions about breastmilk extraction, among other topics related to this issue that should be provided by personnel from health system.

In addition, mothers who participated in the current study stated that when using health services during the postpartum period, they did not find solutions to problems related to breastfeeding. Thus, it is important that all social actors develop efforts for the proper implementation of breastfeeding and exclusive breastfeeding. This should be accompanied by monitoring by personnel from health secretaries, as well as by monitoring morbidity rates of diarrhea favored by early weaning and baby bottle use [36]. In this sense, the non-exclusive breastfeeding was found to be associated with non-revision of the nipples, which play a very important role during the practice. Anatomical abnormalities such as inverted nipples, fissures, cracks and subsequent nipple infection without the advice and accompaniment by health service personnel can lead to early abandonment of breastfeeding [37]. 
Thus, adequate clinical care of the mother during the gestation process is necessary to modify misunderstandings about breastfeeding barriers. One study conducted in Australia, reported that nipple pain was generated by multiple factors in $89 \%$ of cases. Some of the most common causes attributed to nipple pain were: incorrect position of the child, ankyloglossia, infection, insufficient breastmilk production, mastitis, flat or inverted nipples, vasospasm, and palate anomalies. Therefore, early management and treatment of possible factors that could lead to nipples pain and abandonment of breastfeeding were suggested [38]. In addition, mother education regarding breastfeeding, orientations about the correct child position and good grip on the nipples during the first week of life may help to prevent cracks and subsequent infection [39].

WHO estimates that a significant number of child could be saved per year in the world whether all mother breastfed them exclusively during the firsts 6 months of life [40]. In this sense, more studies are needed, especially regarding risk factors in vulnerable communities related to implementation of public health policies with a focus on breastfeeding practice, infant feeding, eating, health habits in pregnant women and under 5 years old children, improving their quality of life and decreasing mortality rates.

\section{Conclusion}

The insufficient practice of breastfeeding in the afrodescendant community was associated with low education level of the mother and being under 18 years old. Despite the high frequency of breastfeeding and exclusive breastfeeding observed in the current study, it is necessary to promote strategies and policies in vulnerable communities to ensure implementation of breastfeeding, considering its multiple benefits.

\section{Authors' Contributions}

\begin{tabular}{|c|c|c|}
\hline $\mathrm{SDC}$ & (D) $0000-0003-1967-8981$ & $\begin{array}{l}\text { Conceptualization, Methodology, Investigation, Formal Analysis, Writing - } \\
\text { Original Draft Preparation and Writing - Review and Editing. }\end{array}$ \\
\hline SCPP & (iD) $0000-0001-9145-8217$ & $\begin{array}{l}\text { Conceptualization, Methodology, Formal Analysis, Writing - Original Draft } \\
\text { Preparation and Writing - Review and Editing. }\end{array}$ \\
\hline LABM & (iD) $0000-0003-0946-9473$ & $\begin{array}{l}\text { Investigation, Writing - Original Draft Preparation and Writing - Review and } \\
\text { Editing. }\end{array}$ \\
\hline
\end{tabular}

\section{Financial Support}

None.

\section{Conflict of Interest}

The authors declare no conflicts of interest.

\section{Acknowledgements}

The authors thank the communities of Tierra Baja, Manzanillo, Caño del Oro and Boquilla.

\section{References}

[1] Koletzko B, Brands B, Chourdakis M, Cramer S, Grote V, Hellmuth C, et al. The Power of Programming and the EarlyNutrition project: opportunities for health promotion by nutrition during the first thousand days of life and beyond. Ann Nutr Metab 2014; 64(3-4):87-96. https://doi.org/10.1159/000365017

[2] Johnston M, Landers S, Noble L, Szucs K, Viehmann L. Breastfeeding and the use of human milk. Pediatrics 2012; 129(3):e827- 41. https://doi.org/10.1542/peds.2011-3552 
[3] Prell C, Koletzko B. Breastfeeding and complementary feeding: recommendations on infant nutrition. Dtsch Arztebl Int 2016; 113(25):435-44. https://doi.org/10.3238/arztebl.2016.0435

[4] Ip S, Chung M, Raman G, Trikalinos TA, Lau J. A summary of the Agency for Healthcare Research and Quality's evidence report on breastfeeding in developed countries. Breastfeed Med 2009; 4(Suppl 1):S17-30. https://doi.org/10.1089/bfm.2009.0050

[5] Gera T, Shah D, Garner P, Richardson M, Sachdev HS. Integrated management of childhood illness (IMCI) strategy for children under five. Cochrane Database Syst Rev 2016; (6): 1-61. https://doi.org/10.1002/14651858.CD010123.pub2

[6] Kramer MS, Chalmers B, Hodnett ED, Sevkovskaya Z, Dzikovich I, Shapiro S, et al. Promotion of Breastfeeding Intervention Trial (PROBIT): a randomized trial in the Republic of Belarus. JAMA 2001; 285(4):413-20. https://doi.org/10.1001/jama.285.4.413

[7] World Health Organization. Indicators for assessing infant and young child feeding practices: conclusions of a consensus. 2008 Washington DC: WHO.

[8] Departamento Administrativo Nacional de Estadísticas. Available from: http://www.dane.gov.co/index.php/estadisticas-por tema/salud/nacimientos-y-defunciones. [ ¿Accessed on September 18, 2017].

[9] Setegn T, Gerbaba M, Belachew T. Determinants of timely initiation of breastfeeding among mothers in Goba Woreda, South East Ethiopia: a cross sectional study. BMC Public Health 2011; 211-17. https://doi.org/10.1186/1471-2458-11-217

[10] Bueno MB, Souza JM, Souza SB, Sampaio da Paz SM, Agostinho SG, Franco AA. Risks associated with the weaning process in children born in a university hospital: a prospective cohort in the first year of life, São Paulo, 1998-1999. Cad Saúde Pública 2003; 19(5):1453-60. https://doi.org/10.1590/So 102-311X2003000500024

[11] Oribe M, Lertxundi A, Basterrechea M, Begiristain H, Santa Marina L, Villar M, et al. Prevalence of factors associated with the duration of exclusive breastfeeding during the first 6 months of life in the INMA birth cohort in Gipuzkoa. Gac Sanit 2015; 29(1):4-9. https://doi.org/10.1016/j.gaceta.2014.08.002

[12] Rodríguez J, Acosta N. Factores asociados a la lactancia materna exclusiva en población pobre de áreas urbanas de Colombia. Rev Salud Pública 2008; 10(1): 71-84. [In Spanish].

[13] Díaz CE, López R, Herrera I, Arena D, Giraldo C, Gonzáles L. Factors associated with breastfeeding in children less than one year of age in the city of Cartagena, Colombia. Colomb Med 201 1; 42(2):26-34.

[14] Acharya P, Khanal V. The effect of mother's educational status on early initiation of breastfeeding: further analysis of three consecutive Nepal Demographic and Health Surveys. BMC Public Health 2015; 15:1069. https://doi.org/10.1186/s12889-015-2405-y

[15] Kimbro RT. On-the-job moms: work and breastfeeding initiation and duration for a sample of low-income women. Matern Child Health J 2006; 10(1):19-26. https://doi.org/10.1007/s 10995-005-0058-7

[16] Calnen G. Paid maternity leave and its impact on breastfeeding in the United States: an historic, economic, political, and social perspective. Breastfeed Med 2007; 2(1):34-44. https://doi.org/10.1089/bfm.2006.0023

[17] Aidam BA, Pérez-Escamilla R, Lartey A. Lactation counseling increases exclusive breastfeeding rates in Ghana. J Nutr 2005; 135(7):1691-5. https://doi.org/10.1093/jn/135.7.1691

[18] Mogre V, Dery M, Gaa PK. Knowledge, attitudes and determinants of exclusive breastfeeding practice among Ghanaian rural lactating mothers. Int Breastfeed J 2016; 11:12. https://doi.org/10.1 186/s13006-016-0071-Z

[19] Onah S, Osuorah DC, Ebenebe J, Ezechukwu C, Ekwochi U, Ndukwu I. Infant feeding practices and maternal sociodemographic factors that influence practice of exclusive breastfeeding among mothers in Nnewi South-East Nigeria: a cross-sectional and analytical study. Int Breastfeed J 2014; 9:6. https://doi.org/10.1186/1746-4358-9-6

[20] Onah HE, Ikeako LC, Iloabachie GC. Factors associated with the use of maternity services in Enugu, southeastern Nigeria. Soc Sci Med 2006; 63(7):1870-8. https://doi.org/10.1016/j.socscimed.2006.04.019

[21] Fotso JC, Ezeh A, Madise N, Ziraba A, Ogollah R. What does access to maternal care mean among the urban poor? Factors associated with use of appropriate maternal health services in the slum settlements of Nairobi, Kenya. Matern Child Health J 2009; 13(1):130-7. https://doi.org/10.1007/s 10995-008-0326-4

[22] Ingram J, Johnson D. A feasibility study of an intervention to enhance family support for breast feeding in a deprived area in Bristol, UK. Midwifery 2004; 20(4):367-79. https://doi.org/10.1016/j.midw.2004.04.003

[23] Bergman M, Nygren-Brunell O, Vilakati D, Målqvist M. Prolonged exclusive breastfeeding through peer support: a cohort study from a community outreach project in Swaziland. J Community Health 2016; 41(5):932-8. https://doi.org/10.1007/s10900-016-0173-y

[24] Persad MD, Mensinger JL. Maternal breastfeeding attitudes: association with breastfeeding intent and sociodemographics among urban primiparas. J Community Health 2008; 33(2):53-60.

https://doi.org/10.1007/s10900-007-9068-2

[25] Bich TH, Cuong NM. Changes in knowledge, attitude and involvement of fathers in supporting exclusive breastfeeding: a community-based intervention study in a rural area of Vietnam. Int J Public Health 2017; 62(Suppl 1):17-26. https://doi.org/10.1007/s00038-016-0882-0 
[26] Rempel LA, Rempel JK, Moore KC. Relationships between types of father breastfeeding support and breastfeeding outcomes. Matern Child Nutr 2017; 13(3):1-14. https://doi.org/10.1111/mcn.12337

[27] Smith PH, Coley SL, Labbok MH, Cupito S, Nwokah E. Early breastfeeding experiences of adolescent mothers: a qualitative prospective study. Int Breastfeed J 2012; 7(1):13. https://doi.org/10.1186/1746-4358-7-13

[28] Swanson V, Power K, Kaur B, Carter H, Shepherd K. The impact of knowledge and social influences on adolescents' breast-feeding beliefs and intentions. Public Health Nutr 2006; 9(3):297-305. https://doi.org/10.1079/phn2006845

[29] Dias de Oliveira L, Justo Giugliani ER, Córdova do Espírito Santo L, Meirelles Nunes L. Counselling sessions increased duration of exclusive breastfeeding: a randomized clinical trial with adolescent mothers and grandmothers. Nutr J 2014; 17:73. https://doi.org/10.1186/1475-2891-13-73

[30] Dehlendorf C, Marchi K, Vittinghoff E, Braveman P. Sociocultural determinants of teenage childbearing among Latinas in California. Matern Child Health J 2010; 14(2):194-201. https://doi.org/10.1007/s 10995-009-0443-8

[31] Machado MM, Assis KF, Oliveira FC, Ribeiro AQ, Araújo RA, Cury AF, et al. Determinants of the exclusive breastfeeding abandonment: psychosocial factors. Rev Saude Publica 2014; 48(6):985-94. https://doi.org/10.1590/So034-8910.2014048005340

[32] Tayebi T, Zahrani ST, Mohammadpour R. Relationship between adequacy of prenatal care utilization index and pregnancy outcomes. Iran J Nurs Midwifery Res 2013; 18(5):360-66.

[33] Yngve A, Sjöström M. Breastfeeding determinants and a suggested framework for action in Europe. Public Health Nutr 2001; 4(2):729-39. https://doi.org/10.1079/phn2001164

[34] Braun MG, Giugliani EJ, Soares MM, Giugliani C, de Oliveira AP, Danelon C M. Evaluation of the impact of the Baby-Friendly Hospital initiative on rates of breastfeeding. Am J Public Health 2003; 93(8):1277-79. https://doi.org/10.2105/ajph.93.8.1277

[35] Carai S, Kuttumuratova A, Boderscova L, Khachatryan H, Lejnev I, Monolbaev K, et al. Review of integrated management of childhood illness (IMCI) in 16 countries in Central Asia and Europe: implications for primary healthcare in the era of universal health coverage. Arch Dis Child 2019; 104(12):1143-9. https://doi.org/10.1136/archdischild-2019-317072

[36] Lamberti LM, Fischer CL, Noiman A, Victoria C, Black RE. Breastfeeding and the risk for diarrhea morbidity and mortality. BMC Public Health 2011; 11(Suppl 3):S15. https://doi.org/10.1186/1471-2458-11-S3-S15

[37] Boskabadi H, Ramazanzadeh M, Zakerihamidi M, Rezagholizade OF. Risk factors of breast problems in mothers and its effects on newborns. Iran Red Crescent Med J 2014; 16(6):e8582. https://doi.org/10.5812/ircmj.8582

[38] Kent JC, Ashton E, Hardwick CM, Rowan MK, Chia ES, Fairclough KA, et al. Nipple pain in breastfeeding mothers: incidence, causes and treatments. Int J Environ Res Public Health 2015; 12(10):12247-63. https://doi.org/10.3390/ijerph 121012247

[39] Dennis CL, Jackson K, Watson J. Interventions for treating painful nipples among breastfeeding women. Cochrane Database Syst Rev 2014; (12):CDo07366. https://doi.org/10.1002/14651858.CDo07366.pub2

[40] World Health Organization. Learning from large-scale community-based programmes improve breastfeeding practices. Geneve: WHO, 2008. 